\title{
Spectroscopic Studies on the Interaction between Tilorone and Human Serum
} Albumin

\author{
Alla V. Yegorova ${ }^{a^{*}}$, Inna I. Leonenko ${ }^{a}$, Yulia V. Scrypynets ${ }^{a}$, Georgy V. Maltsev ${ }^{b}$, \\ Valery P. Antonovich ${ }^{\mathrm{a}}$, Sergey N. Kashutskyy ${ }^{\mathrm{b}}$ \\ ${ }^{a}$ A.V. Bogatsky Physico-chemical Institute of the National Academy of Sciences of Ukraine, \\ Lustdorfskaya doroga 86, Odessa 65080, Ukraine \\ ${ }^{b}$ Open Joint-Stock Ukrainian - Belgian Chemical Enterprise " InterChem ", Lustdorfskaya doroga \\ 86, Odessa 65080, Ukraine \\ yegorova@interchem.com.ua
}

Keywords: fluorenone, human serum albumin, fluorescence quenching, fluorescence resonance energy transfer, thermodynamic parameters.

Abstract. Under physiological conditions, in vitro interaction between the antiviral drug 2,7-bis[2(diethylamino)ethoxy]-9-fluorenone dihydrochloride (Tilorone, TIL) and human serum albumin (HSA) was investigated at excitation wavelength $280 \mathrm{~nm}$ and at different temperatures (298 K and $313 \mathrm{~K}$ ) by fluorescence emission spectroscopy. TIL showed a strong ability to quench the intrinsic fluorescence of HSA through a static quenching procedure. The binding constant is estimated as $K_{A}=7.19 \times 10^{4} \mathrm{~L} \cdot \mathrm{mol}^{-1}$ at $298 \mathrm{~K}$. The enthalpy change $\left(\Delta \mathrm{H}^{\circ}\right)$ and entropy change $\left(\Delta \mathrm{S}^{\mathrm{o}}\right)$ were derived to be negative values. A value of $1.63 \mathrm{~nm}$ for the average distance $r$ between TIL (acceptor) and tryptophan residues of HSA (donor) was derived from the fluorescence resonance energy transfer.

\section{Introduction}

Drug-protein binding has become an important research field in life sciences, chemistry and clinical medicine [1].

Human serum albumin (HSA) serves as the primary transport protein in the human circulation capable of binding reversibly both endogenous and exogenous ligands such as fatty acids, hormones and drugs. It consists of 585 amino acids in a single polypeptide chain [2]. Serum albumin is considered as a model to study the drug-protein interaction in vitro. It is a convenient protein for intrinsic fluorescence measurement due to the presence of tryptophan (Trp) residues which is highly sensitive to its local environment, and can be used to observe changes in the fluorescence emission spectra due to protein conformational changes and binding to substrates [3]. Therefore, study of the interaction between protein and drug molecules will help provide basic information on the pharmacological actions, bio-transformation, bio-distribution of drugs. The binding phenomena will also be useful to explain the 
relationship between the structures and functions of proteins.

There are some popular techniques which have been used to investigate the interaction between drugs and proteins. Fluorescence spectroscopy is one of the powerful techniques to study molecular interactions which changes local environment of fluorophore and helps to predict the binding phenomenon of drugs to proteins [4].

There are a number of reports in the literature, where binding of metabolites, drugs, dyes, fatty acids, bio-active-substances have been studied in detail. So the nature of binding of a ligand with HSA (BSA) is different for different ligands [5 - 25].

In this work, we provide fluorescence spectroscopic investigations on the effect of antiviral drug 2,7-bis[2-(diethylamino)ethoxy]9-fluorenone dihydrochloride (Tilorone, TIL) on the structural and optical properties of human serum albumin. Binding parameters, such as the binding constant, number of sites, binding distance were obtained from the fluorescence data.

\section{Experimental part}

\section{Materials}

HSA was purchased from SigmaAldrich. A $1.010^{-5} \mathrm{~mol} \mathrm{~L}^{-1}$ solution of HSA was prepared by dissolving $66.5 \mathrm{mg}$ in $100 \mathrm{~mL}$ of water. Protein concentration was determined spectrophotometrically by using molar extinction coefficient of $36600 \mathrm{~mol}^{-1} \cdot \mathrm{L} \cdot \mathrm{cm}^{-1}$ at
$280 \mathrm{~nm}[26]$.

TIL solution $\left(1.010^{-3} \mathrm{~mol} \mathrm{~L}^{-1}\right)$ was prepared by dissolving $0.0484 \mathrm{~g}$ of substance in $100 \mathrm{~mL}$ of water. The working solutions were obtained by diluting the stock solution with water. TIL (Scheme 1) was synthesized as described in [27] and appeared antiviral activity.<smiles>CCN(CC)CCOc1ccc2c(c1)C(=O)c1cc(OCCN(CC)CC)ccc1-2</smiles>
Scheme 1. The structure of TIL

Buffer solution was prepared by dissolving $121.14 \mathrm{~g}$ tris (tris(hydroxymethyl) aminomethane) (Sigma-Aldrich) in $800 \mathrm{~mL}$ $\mathrm{H}_{2} \mathrm{O}$, and adjusting the $\mathrm{pH}$ to 7.4 using the appropriate volume of concentrated $\mathrm{HCl}$, diluting to $1000.0 \mathrm{~mL}$ with water $\left(1 \mathrm{~mol} \mathrm{~L}^{-1}\right)$.

All of the used chemicals were of analytical grade or chemically pure. Also highpurity water from Milli-Q system used in the performed.

\section{Apparatus}

Absorption spectra were recorded at room temperature on a UV-2401 PC UV-Vis spectrophotometer (Shimadzu, Japan) equipped with $1.0 \mathrm{~cm}$ quartz cells. Fluorescence spectra were recorded on a on Cary Eclipse Fluorescence spectrometer (Varian, Australia) equipped with a $150-\mathrm{W}$ xenon lamp in a $1-\mathrm{cm}$ quartz cell using an excitation wavelength of $280 \mathrm{~nm}$ over a wavelength range of $285-475 \mathrm{~nm}$ at two temperatures $(298,313 \mathrm{~K})$. The 
excitation and emission bandwidths were $10 \mathrm{~nm}$.

For different temperatures a thermostat bath (WNB 14 Memmert GmbH, Germany) was used. The $\mathrm{pH}$ values of solutions were measured on Lab $850 \mathrm{pH}$ meter (Schott Instruments $\mathrm{GmbH}$, Germany) with a glass electrode.

Data were analyzed using Origin 8.0 software (OriginLab Corporation, Northampton, MA, USA).

\section{Procedures}

$1.00 \mathrm{~mL}$ Tris- $\mathrm{HCl}$ buffer, $1.0 \mathrm{~mL}$ of $1.0 \cdot 10^{-5} \mathrm{~mol} \mathrm{~L}^{-1} \mathrm{HSA}$ solution and a appropriate quantities of the working TIL solution $\left(1 \cdot 10^{-4} \mathrm{~mol} \mathrm{~L}^{-1}, 1 \cdot 10^{-5} \mathrm{~mol} \mathrm{~L}^{-1}\right)$ were transferred to a $10 \mathrm{~mL}$ flask. Then the solution was diluted to $10 \mathrm{~mL}$ with high-purity water. All solutions were mixed thoroughly and kept 5 min before measurements.

The UV/vis absorbance spectra were recorded at room temperature. $1.00 \mathrm{~mL}$ Tris$\mathrm{HCl}$ buffer, $5.0 \mathrm{~mL}$ of $1.0 \cdot 10^{-5} \mathrm{~mol} \mathrm{~L}{ }^{-1} \mathrm{HSA}$ solution and a appropriate quantities of the

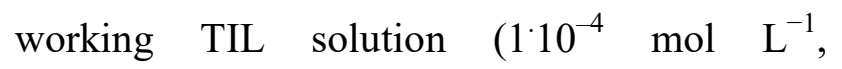
$1 \cdot 10^{-5} \mathrm{~mol} \mathrm{~L}^{-1}$ ) were transferred to a $10 \mathrm{~mL}$ flask. Then the solution was diluted to $10 \mathrm{~mL}$ with high-purity water. A blank system for absorbance spectra of TIL and HAS containing only $1.00 \mathrm{~mL}$ Tris-HCl buffer and diluted to $10 \mathrm{~mL}$ with high-purity water. A blank systems for absorbance spectra of (HSA + TIL) containing $1.00 \mathrm{~mL}$ Tris-HCl buffer, appropriate concentration of tilorone and diluted to $10 \mathrm{~mL}$ with high-purity water.

\section{Results and discussion}

$U V$-vis absorption spectra experiments

$\mathrm{UV}$-vis absorption measurement is a simple and pertinent method that is used to investigate structural changes and to explore complex formation [28]. TIL exhibited one evident peak at $270 \mathrm{~nm}$ (Figure 1, a). To initially verify the quenching mechanism, the UV absorption spectra of (HSA) and difference absorption spectrum between ((HSA + TIL) - TIL) were measured and recorded. As shown in Figure 1, b, HSA possessed two absorption peaks at $220 \mathrm{~nm}$ and $280 \mathrm{~nm}$. The strong absorption peak at around $220 \mathrm{~nm}$ reflected the absorption of the backbone of HSA, while the weak absorption peak at around $280 \mathrm{~nm}$ resulted from the aromatic amino acids (Trp, Tyr, and Phe). With the addition of TIL, the intensity of the peak at $220 \mathrm{~nm}$ was changed with a red shift of about $2 \mathrm{~nm}$, indicating disturbances to the microenvironment around the amide bonds in the protein. The results demonstrated the existence of an interaction between TIL and HSA. The absorption spectrum at around 280 $\mathrm{nm}$ did not shift, indicating that the microenvironment around the aromatic acid residues was not exposed to any change upon HSA-TIL complexation.

\section{Fluorescence quenching spectra}

Any process, which decreases the fluorescence intensity of a sample, is called fluorescence quenching. 

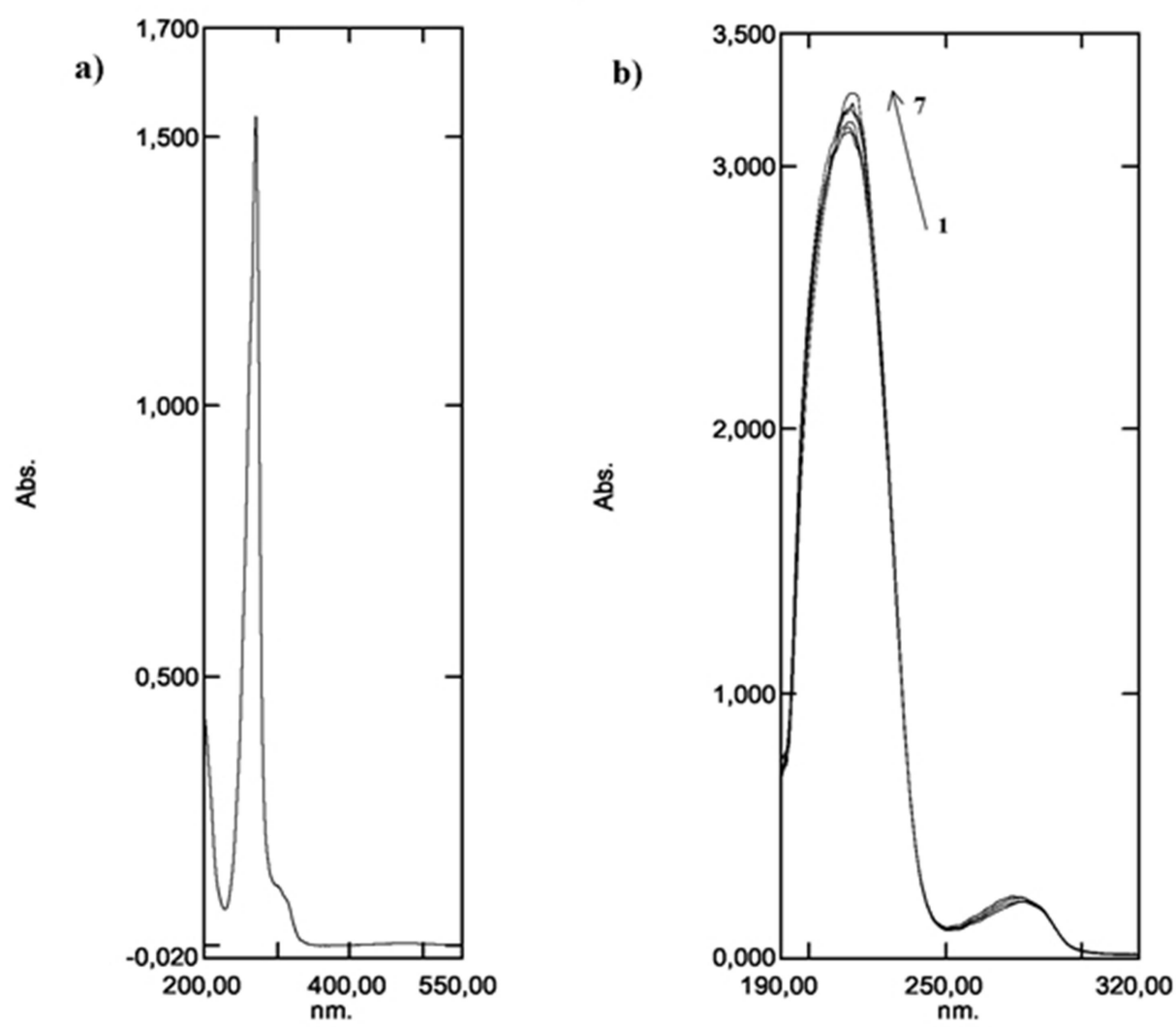

Figure 1. Absorption spectrum of TIL (cTIL $=2.0 \times 10^{-5} \mathrm{~mol} \mathrm{~L}^{-1}$ ) (a); effect of TIL on UV absorption spectra of HSA (b) $\left(\mathrm{T}=298 \mathrm{~K}, \mathrm{pH} 7.4, \mathrm{cHSA}=5 \cdot 10^{-6} \mathrm{~mol} \mathrm{~L}^{-1}\right.$, cTIL $\times 10^{-6} \mathrm{~mol} \mathrm{~L}^{-1}, 1-7$ : $0 ; 1.0 ; 2.0 ; 5.0 ; 7.0 ; 10.0 ; 20.0$ (2-7 - difference absorption spectrum between TIL — HSA and TIL)

The basic principles like excited state accompanied by a $2 \mathrm{~nm}$ blue shift in the reactions, molecular rearrangements, energy emission maximum at the same ligand transfer, ground state complex formation, and collisional quenching involves in molecular interaction, which can result in quenching.

The interaction of TIL with HSA was evaluated by monitoring the intrinsic fluorescence intensity changes of proteins upon addition of TIL (Figure 2). The emission of HSA was characterized by a broad emission band at $346 \mathrm{~nm}$. HSA fluorescence intensity decreased remarkably as TIL concentrations increased. TIL produced $\sim 50 \%$ quenching in HSA fluorescence intensity, which was concentration. The shift in the emission maximum of HSA towards shorter wavelength suggested increased hydrophobicity in the microenvironment of the protein fluorophores upon interaction with this compound [29]. This indicated that TIL could interact with HSA.

Analysis of the emission change of HSA with various amounts of TIL was carried out with the Stern-Volmer equation:

$$
\frac{F_{0}}{F}=1+K_{S V}[Q]=1+k_{q} \tau_{0}[\mathrm{Q}]
$$

where $F_{0}$ and $F$ are the fluorescence intensity in the absence and presence of the quencher, 
respectively, $Q$ the quencher concentration, and $k \mathrm{q}$ the quenching rate constant for a biomolecular reaction, $K_{\mathrm{SV}}$ the Stern-Volmer quenching constant and $\tau_{0}$ is the average lifetime for fluorophore in the absence of quencher evaluated at $10^{-8} \mathrm{~s}[12]$.

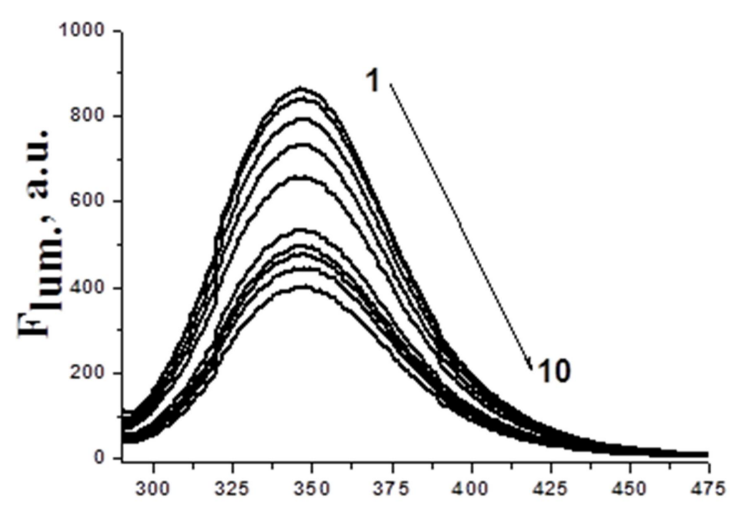

Wavelength, $\mathbf{n m}$

Figure 2. Fluorescence emission spectra of HSA in the presence of TIL various amounts (cTIL ( $\mu \mathrm{mol} \mathrm{L})^{-1}$ ), curves (1-10): 0, 1.0, 2.0, 5.0, $7.0,10.0,20.0,25.0 ; 30.0,35.0 ; \mathrm{pH} 7.4, \lambda_{\text {ex }}=$ $280 \mathrm{~nm}, c \mathrm{HSA}=1 \cdot 10^{-6} \mathrm{~mol} \mathrm{~L}^{-1}, \mathrm{~T}=298 \mathrm{~K}$ )

Figure 3 shows plots of $F_{0} / F$ versus TIL concentrations at different temperatures. They exhibit good linear correlations. It is clear that plots in Fig. 3 are approximately consistent with the Stern-Volmer equation, from which the Stern-Volmer quenching constant $K_{\mathrm{SV}}$ are derived and are listed in Table 1.

A quenching process can be usually induced by a collisional process and/or a formation of a complex between quencher and fluorophore. The values for quenching rate constants in Table 1 are of the magnitude of

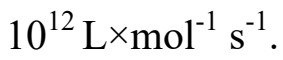

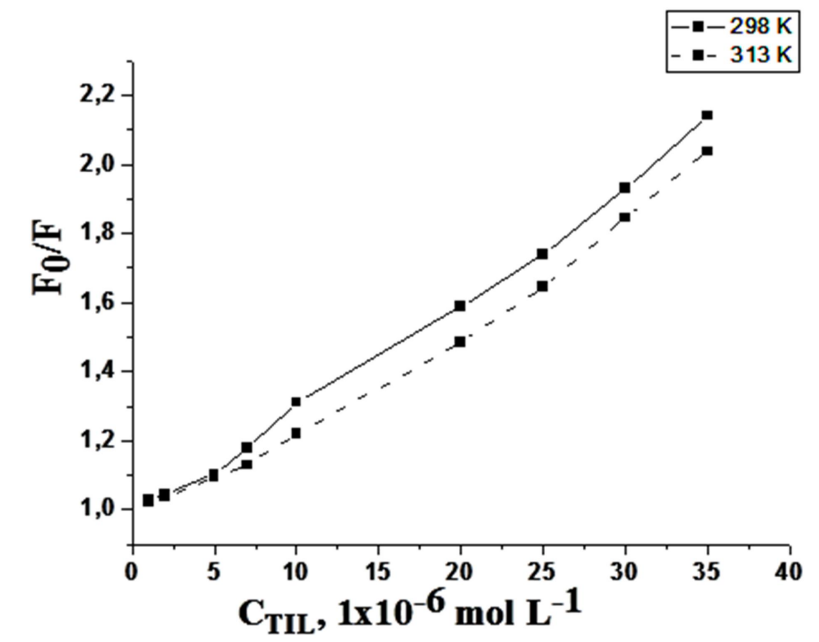

Figure 3. Stern-Volmer plots for quenching of HSA fluorescence by TIL at different temperatures $\left(\mathrm{pH} 7.4, \lambda_{\mathrm{ex}}=280 \mathrm{~nm}\right.$, $\left.c \mathrm{HSA}=1 \cdot 10^{-6} \mathrm{~mol} \mathrm{~L}^{-1}\right)$

Table 1. The Stern-Volmer constants, and quenching constants of the HSA by TIL at different temperatures

\begin{tabular}{|c|c|c|c|}
\hline$T(K)$ & $\begin{array}{c}K_{S V^{*} \times 10^{-4}} \\
\left(L \cdot \mathrm{mol}^{-1}\right)\end{array}$ & $R^{a}$ & $\begin{array}{c}k_{q} \times 10^{-12} \\
\left(\mathrm{~L} \cdot \mathrm{mol}^{-1} \mathrm{~s}^{-1}\right)\end{array}$ \\
\hline 298 & 3.23 & 0.9978 & 3.23 \\
\hline 313 & 2.07 & 0.9949 & 2.07 \\
\hline
\end{tabular}

Obviously, the quenching rate constant $k_{\mathrm{q}}$ for TIL-HSA is greater than that of a scatter process. It may be attributed a quenching process initiated by bio-active substances. So it shows that the above quenching was not initiated by dynamic collision but forms compound, it was static quenching.

Furthermore, linear Stern-Volmer plots may either reveal the occurrence of just a binding site for quencher in the proximity of the fluorophore or indicate the existence of a single 
type of quenching [31].

When small molecules are bound independently to a set of equivalent sites on a macromolecule, the binding constant $\left(K_{\mathrm{A}}\right)$ and sites $(n)$ can be derived from the Eq. (2) [16]:

$$
\log \frac{F_{0}-F}{F}=\log K_{A}+n \log [Q]
$$

where $F_{0}$ and $F$ are the fluorescence intensity in the absence and presence of bio-active substance, respectively.

They still display good linear correlations. The values for $K_{\mathrm{A}}$ and $n$ derived from plots in Fig. 3 according to Eq. (2) are collected in Table 2.

Table 2. Binding constant $K_{A}$, the number of binding sites $n$ and distance between acceptor and donor $r$ at different temperatures and thermodynamic parameters of TIL-HSA interaction at $\mathrm{pH} 7.4$ $\left(\lambda_{\mathrm{ex}}=280 \mathrm{~nm}\right)$

\begin{tabular}{|c|c|c|c|c|c|c|}
\hline$T(K)$ & $K_{A} \cdot \times 10^{-4}\left(L \cdot m o l^{-1}\right)$ & $n$ & $r$ & $\begin{array}{c}\Delta \mathrm{H}^{\mathrm{o}} \\
\left(k J \cdot m o l^{-1}\right)\end{array}$ & $\begin{array}{c}\Delta \mathrm{G}^{\mathrm{o}} \\
\left(k J \cdot m o l^{-1}\right)\end{array}$ & $\begin{array}{c}\Delta \mathrm{S}^{\mathbf{0}} \\
\left(\mathrm{J} \cdot \mathrm{mol}^{-1} \cdot K^{-1}\right)\end{array}$ \\
\hline 298 & 7.19 & 1.08 & 1.63 & \multirow{2}{*}{-33.64} & -27.71 & \multirow{2}{*}{-19.91} \\
\hline 313 & 3.75 & 1.05 & 1.66 & & -27.41 & \\
\hline
\end{tabular}

They indicate that the amount of TIL will affect the pattern of TIL binding to HSA. The influence of temperatures on the TIL binding to HSA is significant. It is obvious that higher temperature will lead to a rapid collision, whereas results in a decrease in the binding strength. As a result, $K_{\mathrm{A}}$ and $n$ will decrease with raising temperature.

Furthermore, the value for $n$ close to one, we may infer that there exists only one kind of binding site on HSA for TIL binding (determined by this method).

Collectively, the fluorescence quenching of HSA by drug was caused by the static quenching, which supported the HSA UV spectral shifts [30].

\section{Binding mode}

The interaction of BSA and small drug molecules may involve hydrophobic forces, electrostatic forces, van der Waals, hydrogen bonds and other interactions. The signs and magnitudes of thermodynamic parameters for protein reactions can be accounted for the main forces contributing to protein stability. The values for the enthalpy change $\left(\Delta H^{\circ}\right)$ and entropy change $\left(\Delta S^{\circ}\right)$ will be derived from the van't Hoff equation by considering $\Delta H^{o}$ not varying significantly over the experimental temperature range:

$$
\ln K_{A}=-\frac{\Delta H^{\circ}}{R T}+\frac{\Delta S^{\circ}}{R}
$$

where $K_{\mathrm{A}}$ is the binding constant at a definite temperature $T$ and $R$ is the gas constant. Consequently, the amount of free energy change $\Delta G^{\mathrm{o}}$ required for the binding is estimated from the following equation:

$$
\Delta G^{\circ}=\Delta H^{\circ}-T \Delta S^{\circ}
$$

From the enthalpy change $\left(\Delta H^{\circ}\right)$ and entropy $\left(\Delta S^{\circ}\right)$, the mode of interaction can be assessed. It is suggested that if $\Delta H^{o}>0$ and $\Delta S^{o}$ 
$>0$, hydrophobic interaction occurs, and if $\Delta H^{o}$

$<0$ and $\Delta S^{o}<0$, Van der Waals and hydrogen bonds dominates, and if $\Delta H^{\circ}<0$ and $\Delta S^{\circ}>0$, is due to electrostatic forces [32]. The data for $\Delta H^{o}$ and $\Delta S^{\circ}$ of TIL binding to HSA are listed in Table 2. With respect to recognized literature data on analogous systems $[19,33]$, the negative values of $\Delta H^{o}$ and $\Delta S^{\circ}$ can be attributed in part to van der Waals forces and in part to the formation of hydrogen bonds.

\section{Energy transfer from HSA to TIL}

Fluorescence resonance energy transfer (FRET) is a distance-dependent interaction between the different electronic excited states of molecules. In this interaction, excitation energy is transferred from one molecule (donor) to another (acceptor) through direct electrodynamic interaction, without emission of a photon from the former molecular system [34]. Energy transfer may occur under the following conditions: when the donor can produce fluorescent light; when there is an overlap between the fluorescence emission spectrum of the donor and the absorbance spectrum of the acceptor; and when the distance between the donor and the acceptor is less than $8 \mathrm{~nm}$. The efficiency of energy transfer between TIL and the HSA Trp214 residue could be used to evaluate the distance between the two using FRET. The overlap of the absorbance spectrum of TIL with the fluorescence emission spectrum of HSA has been shown in Figure 4.
According to Forster's non-radiative resonance energy transfer theory [35], energy transfer efficiency $E$ is related not only to the distance $(r)$ between the bound bio-active molecule (acceptor) and the protein residue (donor), but also to the critical energy transfer distance $\left(R_{0}\right)$.

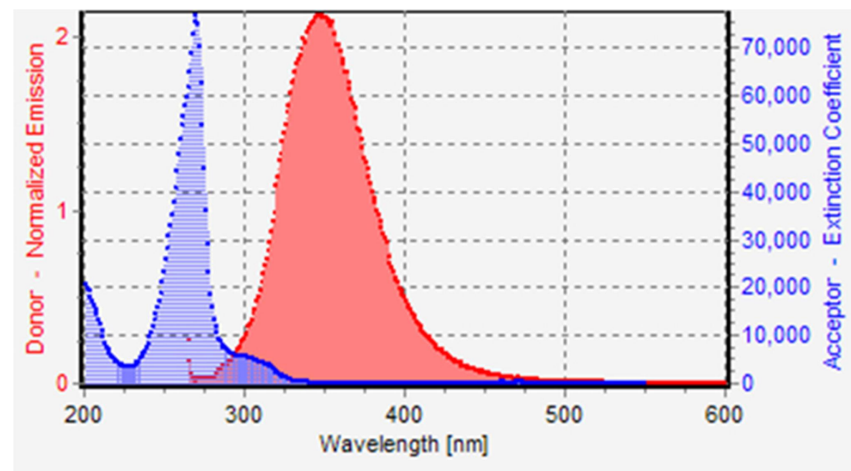

Figure 4. Overlap of the absorption spectrum of TIL (1) with the fluorescence emission spectrum of HSA (2) $(c \mathrm{HSA} / c \mathrm{TIL}=1: 4$, $\left.5 \cdot 10^{-6} \mathrm{~mol} \mathrm{~L}^{-1} ; T=298 \mathrm{~K} ; \lambda_{\mathrm{ex}}=280 \mathrm{~nm}\right)$

By Forster's theory, the efficiency of energy transfer $(E)$ can be calculated according to the following equation:

$$
E=1-F / F_{0}=R_{0}^{6} /\left(R_{0}^{6}+r^{6}\right)
$$

where $r$ is the distance between acceptor (TIL) and donor (HSA), and $R_{0}$ is the critical distance when the transfer efficiency is $50 \%$. The value of $R_{0}$ is calculated using the following equation: $R_{0}^{6}=8.79 \times 10^{-25} K^{2} n^{-4} \varphi J$ where $K^{2}$ is the spatial orientation factor of the dipole; $n$ is the refractive index of the medium; $\varphi$ is the fluorescence quantum yield of donor; and $J$ is the spectral overlap between the emission spectrum of donor and the absorption spectrum of acceptor (Figure 4), given by: 


$$
J=\frac{\int_{0}^{\infty} F(\lambda) \varepsilon(\lambda) \lambda^{4} d \lambda}{\int_{0}^{\infty} F(\lambda) d \lambda}
$$

where $F(\lambda)$ is the normalized fluorescence intensity of the donor at wavelength $\lambda$, and $\varepsilon(\lambda)$ is the molar absorption coefficient of the acceptor at wavelength $\lambda$. In the present case, $K^{2}$ $=2 / 3, n=1.336$, and $\varphi=0.118[36]$. Hence, from equations (5)-(7), we could calculate the following parameters are listed in Table 3. In conclusion, the distance $(r)$ between HSA
Trp214 and bound TIL was much less than 8 $\mathrm{nm}$, and accorded with the relationship $0.5 R_{0}<r$ $<1.5 R_{0}$. This implied that the non-radiative energy transfer from HSA to TIL occurred with high possibility, which was in accordance with the occurrence of a static quenching mechanism. This result indicated that the binding obeyed the conditions of Forster's energy transfer. A comparison of the $J, R_{0}$ and $r$ values of different ligands bound to proteins is given in Table 3 .

Table 3. Comparative assessment of the TIL (ligand) distance to protein's fluorophore (HSA) measured by Forster's nonradiative energy transfer with other ligands bound to proteins

\begin{tabular}{|c|c|c|c|c|c|}
\hline Ligand & Protein & $J\left(\mathrm{~cm}^{3} \mathrm{~L} \mathrm{~mol}^{-1}\right)$ & $R_{0}(\mathrm{~nm})$ & $r(\mathrm{~nm})$ & References \\
\hline mitoxantrone & HSA & $1.67 \times 10^{-15}$ & 0.48 & 2.64 & {$[5]$} \\
\hline imidacloprid & HSA & $3.17 \times 10^{-15}$ & 1.52 & 2.10 & {$[6]$} \\
\hline captopril & HSA & $1.09 \times 10^{-18}$ & 2.37 & 1.05 & {$[7]$} \\
\hline $\begin{array}{c}\text { pyrimidine-annulated } \\
\text { spiro-dihydrofuran }\end{array}$ & BSA & $9.14 \times 10^{-16}$ & 1.71 & 2.59 & {$[8]$} \\
\hline eupatorin & BSA & $1.79 \times 10^{-14}$ & 1.56 & 1.64 & {$[9]$} \\
\hline erlotinib hydrochloride & BSA & $3.89 \times 10^{-21}$ & 2.00 & 2.20 & {$[10]$} \\
\hline sanguinarine & BSA & $1.29 \times 10^{-14}$ & 2.63 & 2.38 & {$[11]$} \\
\hline carbamazepine & BSA & $3.24 \times 10^{-15}$ & 2.11 & 3.60 & {$[12]$} \\
\hline naringin & BSA & $3.24 \times 10^{-15}$ & 2.32 & 3.25 & {$[13]$} \\
\hline 3-carboxyphenoxathiin & BSA & $1.63 \times 10^{-15}$ & 1.86 & 1.86 & {$[14]$} \\
\hline paclobutrazol & HSA & $1.35 \times 10^{-14}$ & 2.58 & 4.41 & {$[15]$} \\
\hline pazufloxacin mesilate & BSA & $9.93 \times 10^{-15}$ & 2.45 & 4.04 & {$[16]$} \\
\hline benzidine & trypsin & $3.92 \times 10^{-15}$ & 2.67 & 2.97 & {$[17]$} \\
\hline nevadensin & lysozyme & $8.17 \times 10^{-15}$ & 2.41 & 2.28 & {$[18]$} \\
\hline farrerol & lysozyme & $5.19 \times 10^{-14}$ & 2.07 & 2.67 & {$[19]$} \\
\hline fosfomycin & BSA & $1.87 \times 10^{-14}$ & 2.83 & 4.99 & {$[24]$} \\
\hline sulfamethoxazole & HSA & $1.70 \times 10^{-16}$ & 2.79 & 3.89 & {$[25]$} \\
\hline tilorone (presented study) & HSA & $7.88 \times 10^{-16}$ & 1.67 & 1.63 & this work \\
\hline
\end{tabular}

\section{Conclusions}

In this work, the interaction between TIL and serum albumin (HSA) have been investigated by fluorescence method combined with UV-vis spectroscopy techniques under simulative physiological condition. The experiment results indicate that TIL quenches the intrinsic fluorescence of proteins through 
static quenching mode of TIL-HSA system, which supported the HSA UV spectral shifts and the decreasing binding constant for TIL and HSA complex with increasing temperature indicates the decomposition of the system.

The values of binding constant and the number of binding sites of the TIL-HSA system are determined using the Stern-Volmer equation. The average binding distance between donor and acceptor molecules is found to be $1.63 \mathrm{~nm}$ for HSA - TIL systems from the Forster non-radioactive resonance energy transfer theory.

Since, the pharmaceutical firms need standardized screens for protein binding in the first step of new drug design, this kind of study of interaction between HSA with TIL would be useful in pharmaceutical industry and clinical medicine.

\section{Acknowledgements}

The authors acknowledge financial support from the National Academy of Sciences of Ukraine.

\section{References}

[1] Gentili PL, Ortica F, Favaro G. Static and Dynamic Interaction of a Naturally Occurring Photochromic Molecule with Bovine Serum Albumin Studied by UV-Visible Absorption and Fluorescence Spectroscopy. J. Phys. Chem. B 2008; 112: 16793-16801.

[2] Tian JN, Liu JQ, He W, Hu ZO, Yao XJ, Chen XG. Probing the Binding of Scutellarin to Human Serum Albumin by
Circular Dichroism, Fluorescence Spectroscopy, FTIR and Molecular Modeling Method. Biomacromolecules 2004; 5: 1956-1961.

[3] Peters T. All about Albumin: Biochemistry, Genetics, and Medical Applications; Academic Press: San Diego, CA, USA, 1996, 432 p.

[4] Kwon S, Carson JH. Fluorescence Quenching and Dequenching Analysis of RNA Interactions in Vitro and in Vivo. Anal. Biochem. 1998; 264: 133-140.

[5] Khan SN, Islam B, Yennamalli R, Sultan A, Subbarao N, Khan AU. Interaction of mitoxantrone with human serum albumin: Spectroscopic and molecular modeling studies. Europ. J. Pharm. Sci. 2008; 35: 371-382.

[6] Wang Y, Tang B, Zhang H, Zhou Q, Zhang G. Studies on the interaction between imidacloprid and human serum albumin: Spectroscopic approach. J. Photochem. Photobiol. B: Biology 2009; 94: 183-190.

[7] Gao X, Tang Y, Rong W, Zhang $\mathrm{X}$, Zhao W, Zi Y. Analysis of binding interaction between captopril and human serum albumin. Amer. J. Anal. Chem. 2011; 2: 250-257.

[8] Swarup Roy, Sintu Ganai, Raj Kumar Nandi, KC. Majundar, Tapan K. Das. Studies of the interaction of bovine serum albumin with pyrimidine-annulated spirodihydrofuran and its biological activities. Adv. Mater. Lett. 2015; 6(11):1018-1024.

[9] Xu H, Yao N, Xu H, Wang T, Li $\mathrm{G}$ and $\mathrm{Li} \mathrm{Z}$. Characterization of the interaction 
between eupatorin and bovine serum albumin by spectroscopic and molecular modeling methods. Int. J. Mol. Sci. 2013; 14: 1418514203.

[10] Rasoulzadeh F, Asgari D, Naseri A, Rashidi MR. Spectroscopic studies on the interaction between erlotinib hydrochloride and bovine serum albumin. DARU 2010; 18: 179184.

[11] Hossain M.; Khan A Y and Kumar G S Interaction of the anticancer plant alkaloid sanguinarine with bovine serum albumin. PLOS One 2011; 6 e18333 (www.plosone.org).

[12] Wang C, Wu Q-H, Wang Z, Zhao J. Study of the interaction of carbamazepine with bovine serum albumin by fluorescence quenching method. Anal. Sci. 2006; 22: 435438.

[13] Roy AS, Tripathy DR, Chatterjee A, Dasgupta S. A spectroscopic study of the interaction of the antioxidant naringin with bovine serum albumin. J. Biophys. Chem. 2010; 1: 141-152.

[14] Varlan A, Hillebrand M. Bovine and human serum albumin interactions with 3carboxyphenoxathiin studied by fluorescence and circular dichroism spectroscopy. Molecules. 2010;15: 3905-3919.

[15] Dong S, Li Z, Shi L, Huang G, Chen S, Huang T. The interaction of plantgrowth regulators with serum albumin: Molecular modeling and spectroscopic methods.
Food Chem. Toxicol. 2014; 67: 123-130.

[16] Jin $J$ and Zhang $X$. Spectrophotometric studies on the interaction between pazufloxacin mesilate and human serum albumin or lysozyme. J. Lumin. 2008; 128: 81-86.

[17] Zhang HM, Wangn YQ, Zhou QH. Fluorimetric study of interaction of benzidine with trypsin. J. Lumin. 2010; 130: 781-786.

[18] Li D, Zhu J, Jin J. Spectrophotometric studies on the interaction between nevadensin and lysozyme. J. Photochem. Photobiol. A: Chemistry 2007; 189: 114-120.

[19] Zhu J, Li D, Jin J, Wu L. Binding analysis of farrerol to lysozyme by spectroscopic methods. Spectrochim. Acta Part A 2007; 68: 354-359.

[20] Gowda B, Mallappa M, Gowda J, Rengasamy R. Interaction of ketoconazole with bovine serum albumin: electrochemical, spectroscopic and molecular modeling studies J. Appl. Pharm. Sci. 2015;5: 037-044.

[21] Abu Teir MM, Ghithan J, AbuTaha MI, Darwish SM, Abu-hadid MM. Spectroscopic approach of the interaction study of ceftriaxone and human serum albumin. J. Biophys. Struct. Biol. 2014; 6: 1-12.

[22] Hamdi O, Feroz S, Shilpi J, Anouar El H, Mukarram A, Mohamad SB, Tayyab S, Awang K. Spectrofluorometric and molecular docking studies on the binding of 
curcumenol and curcumenone to human serum albumin. Int. J. Mol. Sci. 2015; 16: 5180-5193.

Salam MA, Rokonujjaman $\mathrm{M}$, Rahman A, Sultana UN, Zakir SM. Study of in Vitro Interaction of Sildenafil Citrate with Bovine Serum Albumin by Fluorescence Spectroscopy. Pharmacology \& Pharmacy. 2015; 6: 94-101.

[24] Manjunath D Meti, Sharanappa T Nandibewoor, Shrinivas D Joshi, Uttam A More, Shivamurti A Chimatadar. Multispectroscopic investigation of the binding interaction of fosfomycin with bovine serum albumin. J Pharm. Anal. 2015; 5: 249-255.

[25] Praveen N Naik, Sharanappa T Nandibewoor, Shivamurthi A Chimatadar. Noncovalent binding analysis of sulfamethoxazole to human serum albumin: Fluorescence spectroscopy, UV-vis, FT-IR, voltammetric and molecular modeling. J Pharm. Anal. 2015; 5: 143-152.

[26] Khan SN, Islam B, Khan AU. Probing midazolam interaction with human serum albumin and its effect on structural state of protein. Int. J. Integ. Biol. 2007; 1: 102-112.

[27] Andrews E.R., Fleming R.W., Grisar J.M., Kihm J.C., Wenstrup D.L., Mayer G.D. Bis-basic-substituted polycyclic aromatic compounds. A new class of antiviral agents. 2. Tilorone and related bis-basic ethers of fluorenone, fluorenol, and fluorine. J.Med.Chem. 1974; 17(8): $882-886$.

[28] Valeur B, Brochon JC. New
Trends in Fluorescence Spectroscopy 6th edn (Berlin :Springer); 1999, pp. 25-28.

[29] Lakowicz JR Principles of Fluorescence Spectroscopy 3rd edn New York:Springer; 2006; 954 p.

[30] Sahoo BK, Ghosh KS, Dasgupta S. Molecular interactions of isoxazolcurcumin with human serum albumin: Spectroscopic and molecular modeling studies. Biopolymers 2009; 91: 108-119.

[31] Silva D, Cortez CM, CunhaBastos J, Louro SRW. Methyl parathion interaction with human and bovine serum albumin. Toxicol. Lett. 2004; 147: 53-61.

[32] Ross P D, Subramanian S. Thermodynamics of protein association reactions: Forces contributing to stability. Biochemistry. 1981; 20: 3096-3102.

[33] Aki H, Yamamoto M. Thermodynamics of the binding of phenothiazines to human plasma, human serum albumin and alpha 1-acid glycoprotein: a calorimetric study. J. Pharm. Pharmacol. 1989; 41: 674-679.

[34] Forster T. Zwischenmolekulare energiewanderung und fluoreszenz. Ann. Phys. 1948; 2: 55-75.

[35] Wu P, Brand L. Resonance energy transfer: Methods and applications. Anal. Biochem. 1994; 218: 1-13.

[36] Xiao, J.B.; Shi, J.; Cao, H.;Wu, S.D.; Ren, F.L.; Xu, M. Analysis of binding interaction between puerarin and bovine serum 
albumin by multi-spectroscopic method. J.

Pharmaceut. Biomed. 2007; 45: 609-615. 